\title{
Drought tolerance of faba bean (Vicia faba L.) can be improved by specific LED light wavelengths
}

\author{
L. HUANG, Y. XIAO, J. RAN, L. WEI, Z. LI, Y. LI, X. ZHANG, L. LIAO, D. WANG, X. ZHAO, \\ Q. XIAO, and Y. GUO \\ College of Agronomy and Biotechnology, Southwest University, 400716 Chongqing, China
}

\begin{abstract}
A light wavelength affects both plant photomorphogenesis and stress resistance. In this study, the phenotypic plasticity (growth parameters and cuticular waxes) and physiological adaptation (photosynthetic properties and antioxidant enzyme activities) of faba bean subjected to specific LED lights, red, yellow, blue, violet, and white, were analyzed under two water conditions (normal and drought). The plants grown under red and yellow lights possessed the smaller leaf size and the higher leaf relative water content. The blue light had a positive effect on improving stomatal conductance and net photosynthetic rate of faba bean leaves, and the plants grown under the blue light also had higher antioxidant enzyme activities. The blue light also changed the dominant wax component to alkanes and significantly decreased a total wax load under the drought stress, and thus minimized the cuticle transpiration (water loss). The decreased wax deposition and the increase of $\mathrm{C}_{31}-\mathrm{C}_{33}$ alkanes abundance in plants grown under the yellow light also resulted in a lower leaf water loss under the drought stress. The red light increased but the violet light did not change the cuticle water loss. These results suggest that plant drought tolerance could be improved by supplementing the blue and yellow lights.
\end{abstract}

Additional key words: cuticle resistance; morphological adaptation; physiological responses; wax chemical profile.

\section{Introduction}

Light is essential for plant life and acts as an important energy source and signal, thereby dramatically altering plant survival and development (de Wit et al. 2016). However, the depletion of the ozone layer, cloud cover, and the increase of air pollutants induced by adverse climate changes, continuously imposed a strong effect on the scattering and the fluence rates of visible light and ultraviolet radiation (Schiedek et al. 2007, Williamson et al. 2014). Such changes in light conditions reduce the assimilation and transpiration rate and the crop resistance to disease and pests. For example, elevated UV-B radiation reduced the photosynthesis efficiency and increased lipid peroxidation in radish (Singh et al. 2012), low light stress adversely affected starch biosynthesis and resulted in the reduction of rice grain yield (Kumar et al. 2019), and canopy shade influenced overall the radiation balance and increased pathogens infection and herbivory (Roberts and Paul 2006).

Light emitting diodes (LEDs) have been successfully introduced to modern facility agriculture (urban agriculture, horticultural application, etc.) due to their technical advantages over traditional light sources, for example, longevity, high radiation efficiency, and low thermal output, with specific wavelengths control from UV-C $(250 \mathrm{~nm})$ to infrared light $(1000 \mathrm{~nm})$ and adjustable light intensities (Bourget 2008, Morrow 2008, Olle and Viršile 2013). Highlighted advantages of LEDs provide possibility to optimize specific wavelengths selection in improving plant production (Choi et al. 2015). LEDs with specific wavelengths were also used in the improvement of plant resistance, such as drought tolerance and disease resistance (Wang et al. 2010, Kim et al. 2013, Ahmadi et al. 2019). For example, far red illumination improved the resistance of cotton (Gossypium hirsutum L.) to drought stress by remaining a higher stomatal resistance, leaf turgor, and lower rate of transpiration (Ouedraogo and Hubac 1982). Pretreatment of plants with red + blue LEDs could improve the resistance of lemon balm to drought stress and remain their growth and quality (Ahmadi et al. 2019). These results suggested that LEDs could be applied

\footnotetext{
Received 18 April 2020, accepted 7 July 2020.

+Corresponding author; e-mail: qhgyj@,126.com

Abbreviations: AN - available nitrogen; AP - available phosphorus; APX - ascorbate peroxidase; BSTFA - bis-N,O-trimethylsilyltrifluoroacetamide; CAT - catalase; $C_{\mathrm{i}}$ - intercellular $\mathrm{CO}_{2}$ concentration; DM - dry mass; $E$ - transpiration rate; FID - flame ionization detector; FM - fresh mass; $g_{\mathrm{s}}$ - stomatal conductance; GR - glutathione reductase; LEDs - light emitting diodes; MDA malondialdehyde; $P_{\mathrm{N}}$ - net photosynthetic rate; POD - peroxidase; ROS - reactive oxygen species; RWC - relative water content; $\mathrm{SM}$ - saturated mass; SOD - superoxide dismutase; TBA - thiobarbituric acid; TCA - trichloroacetic acid; TK - total potassium; TN - total nitrogen; TP - total phosphorus; VLCFAs - very long chain fatty acids.

Acknowledgements: This work was financially supported by National Natural Science Foundation of China (NSFC, No. 31670407 and 31771694) and the Fundamental Research Funds for the Central Universities (XDJK2018B021).
} 
on drought-stressed crops to improve their resistance.

Drought stress is the most common and damaging environmental stress to global agriculture production and food security (Farooq et al. 2009, Patwari et al. 2019). Plants have developed a range of strategies to cope with drought, varying from morphological to molecular responses, showing physiological and biochemical adaptation. For example, reduced leaf size, higher root-shoot ratios and increased stomatal and cuticular resistance are the major adaptations to minimize transpiration water loss (Lei et al. 2006). Reactive oxygen species (ROS) overproduction in cellular organelles is the earliest cellular response under drought stress, but plants enhance the antioxidants (enzymatic and nonenzymatic antioxidants) to scavenge ROS against oxidative damage to lipids, proteins and other macromolecules (Scandalios 2005, Hussain et al. 2008, Manivannan et al. 2008, Ozkur et al. 2009, Yuan et al. 2010). Accumulation of some secondary metabolites such as carotenoids in photosynthetic organisms, which act as ROS scavengers and have photoprotective functions, is also vital in driving photosynthesis and carbon fixation under monochromatic lights (Sytar et al. 2019, Landi et al. 2020). Stomatal limitation (stomatal closure and reduced stomatal size) is responsible for the decline of photosynthetic rate and minimizes transpirational losses under drought stress (Medrano et al. 2002, Yamane et al. 2003). Furthermore, limiting nonstomatal water loss and improving cuticular resistance are also key adaptations of plants to cope with drought stress (Raven and Edwards 2004). However, there is little information on the effect of specific LED wavelengths on plant cuticle resistance to drought stress.

Plant cuticle is the main barrier against water loss (Kerstiens 1996). When the stomata are closed under drought stress, the survival of plant depends on the amount of water loss through the cuticle (Kerstiens 1996). The cuticle membrane consists of two lipid fractions: the polymer matrix (cutin polymer) and cuticular wax. Cuticular wax is the outermost hydrophobic layer of cuticle, which can modulate light reflectance, hence regulate the temperature and limit transpiration water loss (Shepherd and Griffiths 2006, Guo et al. 2017). Studies have shown that the responses of cuticular wax deposition to changing environments are related to plant adaptations ( $\mathrm{Bi}$ et al. 2017, Yeats and Rose 2013). In general, an increase of wax deposition under drought conditions has been shown to be related to plant adaptations to water deficit ( $\mathrm{Li}$ et al. 2019). Total wax load reduced by $63 \%$ in $w 3$ wheat mutant caused significant increase of cuticle permeability (Zhang et al. 2015). Transgenic Camelina plants overexpressing Arabidopsis MYB96 exhibited significantly increased total wax loads and enhanced drought tolerance (Lee et al. 2014). However, some studies showed that cuticle water permeability was not related to the wax coverage (Riederer and Schreiber 2001), suggesting that cuticular wax amount alone may not be important and sufficient to evaluate epidermal transpiration (Ristic and Jenks 2002).

Cuticular wax mixture is composed of very long chain fatty acids (VLCFAs) and its derivatives, including aldehydes, ketones, primary and secondary alcohols, diols, ketols, diketones, alkyl esters, and alkanes (Jetter et al. 2008, Guo and Jetter 2017). Increasing studies have shown that cuticular wax permeability is correlated with the proportion of nonpolar wax compounds, such as alkanes (Buschhaus and Jetter 2012, Parsons et al. 2012). Panikashvili et al. (2007) also found that the decrease of wax monomers, especially $\mathrm{C}_{29}$ alkane, contributed to the decline of drought tolerance. Distinct deposition of alkanes in wax compositions resulted in the different drought tolerance in three watermelon germplasms, particularly the depositions of $\mathrm{C}_{29}$ and $\mathrm{C}_{31}$ alkanes (Li et al. 2020). Other wax compound, such as wax ester, has been also shown to be related to drought resistance for Arabidopsis (Patwari et al. 2019). Light can regulate the waxy genes expression (Hooker et al. 2002, Go et al. 2014), thus influencing wax quantity and compositions. Higher irradiation levels increased wax thickness in many plants, including various Brassica sp. (Shepherd et al. 1995), barley (Giese 1975), and carnation (Reid and Tukey 1982). Light altered the balance of wax biosynthesis between various components in Brassica oleracea leaves, increased the synthesis of $\mathrm{C}_{29}$ (paraffin, ketone, and secondary alcohol) but decreased the synthesis of aldehydes and esters (Macey 1970). Increased light intensity decreased the ester amount but increased the secondary alcohol amount in velvetleaf epicuticular wax (Hatterman-Valenti et al. 2011). However, it is still not clear whether LED light would also alter wax compositions and thus improve the plant drought resistance.

Faba bean, a major grain legume, is widely distributed all over the China. In south of China, faba bean is sown in autumn, but the lack of solar radiation during late winter and early spring results in the shortening of flowering period and reduction of flower and pod number and consequently decreasing its grain yield (Xia 2001, Randhir and Shetty 2003). Therefore, in this study, faba bean plants grown under drought conditions were supplemented with four monochromatic LEDs, aiming to analyze the roles of LEDs in improving plant drought resistance through the alterations of plant physiological parameters (photosynthesis properties and antioxidant enzymes activities) and cuticular waxes. The following aspects were mainly addressed: (1) The variations of morphological and physiological responses to drought stress under different light wavelengths. (2) How the cuticular waxes were influenced by light wavelength under drought stress conditions? (3) How much did the light wavelength contribute to the drought tolerance of faba bean? We hypothesized that certain light wavelength might improve plant drought resistance by adjusting plant physiological responses and cuticular wax depositions.

\section{Materials and methods}

Plant growth conditions and materials: The experiment was carried out in a greenhouse at Southwest University, Chongqing $\left(29^{\circ} 49^{\prime} \mathrm{N}, 106^{\circ} 25^{\prime} \mathrm{E}\right)$, China. It is a typical low radiation region, and the average annual sunshine duration is $1,000-1,400 \mathrm{~h}$, and the percentage of sunshine is only $25-35 \%$. The area has a mean temperature of $17.8^{\circ} \mathrm{C}$ and a mean annual rainfall of $1,100 \mathrm{~mm}$ during the last 30 years. 
Faba bean is grown in a rotation and intercropping system in these areas. As the biggest autumn planting area, the planting area reached $55 \%$ of the total faba bean planting area in China.

Faba bean (Vicia faba cv. Qidou 2) seeds were supplied by Qin Yuan Chun Seeds Co., Ltd., Huaian, China. This cultivar is a medium maturing and high-yield variety widely distributed in the south of China (Ma et al. 2002). As a fall sowing cultivar, it was bred by selecting the natural mutants from Qidou 1 population through systematic selection for many generations. Faba bean seeds were surface sterilized with $3 \% \mathrm{H}_{2} \mathrm{O}_{2}$ and then sowed in $2 \mathrm{~cm}$ depth equidistantly in a plastic pot with $23 \mathrm{~cm}$ diameter by $18 \mathrm{~cm}$ height filled with a mixture of soil, peat, and vermiculite $(2: 1: 1)$. The soil was a yellow soil, sampled from $0-20 \mathrm{~cm}$ layer, air dried, and wet sterilized at $121^{\circ} \mathrm{C}$ for $30 \mathrm{~min}$. The mixture soil $\mathrm{pH}$ was 6.23 , the available nitrogen (AN) and phosphorus (AP) concentrations were 228.67 and $96.96 \mathrm{mg} \mathrm{kg}^{-1}$, respectively. The organic carbon, total nitrogen (TN), phosphorus (TP), and potassium (TK) were $34.04,3.21,3.60$, and $8.67 \mathrm{~g} \mathrm{~kg}^{-1}$, respectively.

Experimental design: A two-way completely randomized factorial design was employed (water conditions and light spectra) with four replicates. In total, eight pots were placed in the greenhouse receiving red $(637 \mathrm{~nm})$, blue $(458 \mathrm{~nm})$, yellow $(600 \mathrm{~nm})$, and violet $(403 \mathrm{~nm})$ lights provided by LED lights (Shenzhen Glamorous Lighting Technology Co., Ltd., Shenzhen, China), separately. White LED light was set as the control. The light spectra were measured with Hipoint HR-350 spectrometer and were shown in Fig. 1S (supplement). The temperature of the greenhouse was $25 / 20^{\circ} \mathrm{C}$ (day/night) and the relative humidity ranged from 65 to $75 \%$. The position of the pots was adjusted every three days to make sure the plant top receiving PPFD of $50 \mu \mathrm{mol} \mathrm{m}{ }^{-2} \mathrm{~s}^{-1}$ during a photoperiod of $12 / 12 \mathrm{~h}$ (light/dark). One week after germination, seedlings were thinned to six plants per pot. After four weeks, when faba bean were in four-leaf stage, half of the pots (four pots) were subjected to drought stress (withholding the water until the soil water content reached 45 to $50 \%$ of field water capacity). The control plants were well-watered and kept at 75 to $80 \%$ of field water capacity. Fifteen days after drought treatment, the leaves from each pot were sampled for the following measurements.

Plant growth parameters: Plant height of faba bean seedlings was measured by a ruler. Leaves were sampled and photos were taken to measure the surface area by Image $J$ software. Stem diameter of plants was measured using a vernier calipers.

To measure the relative water content of faba bean leaves, the fourth fully expanded leaves were sampled and weighed (fresh mass, FM). Leaf samples were then immersed into the distilled water for $24 \mathrm{~h}$ at room temperature and the saturated mass was measured (SM). Next, the leaves were dried in an oven at $70^{\circ} \mathrm{C}$ for $24 \mathrm{~h}$ and the dry mass was obtained (DM). Relative water content (RWC) of leaves was calculated as follows (Smart and Bingham 1974): RWC $[\%]=(F M-D M) /(S M-D M) \times 100$.
Photosynthesis parameters measurements were made on the fourth fully expanded leaves using a portable photosynthesis system (6400XT, LI-COR, Lincoln, NE, USA) from 9:30 to $10: 30 \mathrm{~h}$ with the PAR at 1,000 $\mu \mathrm{mol}$ $\mathrm{m}^{-2} \mathrm{~s}^{-1}$ and ambient $\mathrm{CO}_{2}$ concentration at $400 \mu \mathrm{mol} \mathrm{mol}{ }^{-1}$. The photosynthesis parameters included net photosynthetic rate $\left(P_{\mathrm{N}}\right)$, transpiration rate $(E)$, stomatal conductance $\left(g_{\mathrm{s}}\right)$, and intercellular $\mathrm{CO}_{2}$ concentration $\left(C_{\mathrm{i}}\right)$.

Antioxidant enzymes activities, malondialdehyde and soluble protein content: For assay of antioxidant enzymes, $0.15 \mathrm{~g}$ fresh faba bean leaves were homogenized in $1.5 \mathrm{~mL}$ of $50 \mathrm{mmol} \mathrm{L}^{-1}$ Tris- $\mathrm{HCl}$ buffer ( $\mathrm{pH} 7.0$ ) as described by Li et al. (2002), and then centrifuged at $12,000 \times \mathrm{g}$ for $20 \mathrm{~min}$ at $4^{\circ} \mathrm{C}$. The supernatant was used for the determination of superoxide dismutase (SOD, EC 1.15.1.1), peroxidase (POD, EC 1.11.1.7), catalase (CAT, EC 1.11.1.6), ascorbate peroxidase (APX, EC 1.11.1.11), and glutathione reductase (GR, EC 1.6.4.2) activities.

POD activity was measured following the guaiacol method described by Chance and Maehly (1955) with some modifications. The activity of SOD was measured using the nitroblue tetrazolium (NBT) method (Giannopolitis and Ries 1977). CAT activity was determined according to the method of Aebi (1984) by measuring the rate of decomposition of $\mathrm{H}_{2} \mathrm{O}_{2}$ at $240 \mathrm{~nm}$. Change of absorbance at $290 \mathrm{~nm}$ caused by ascorbate oxidation was used to determine the APX activity. GR activity was assayed according to the method of Halliwell and Foyer (1978) with minor modification. The absorbance was measured by a spectrophotometer (T6, PERSEE, China).

MDA content was measured by thiobarbituric acid (TBA) method (Dhindsa et al. 1981). Fresh leaf sample (1 g) was homogenized in $10 \mathrm{~mL}$ of $10 \%$ trichloroacetic acid (TCA) and then centrifuged at 3,000 $\times g$ for $10 \mathrm{~min}$. MDA content was calculated by the absorbance at 532, 600 , and $450 \mathrm{~nm}$.

Soluble protein was extracted from faba bean leaves and estimated by the method of Bradford (1976) with bovine serum albumin as a standard.

Cuticular wax extraction and analysis: Leaf cuticular wax samples were collected from the fourth fully expanded leaves and photographed to measure the surface area using Image $J$ software before wax extraction. Each sample was placed into a glass tube with $4 \mathrm{~mL}$ of chloroform containing $5 \mu \mathrm{g} n$-tetracosane as an internal standard. Tissues were agitated on a vortex for $30 \mathrm{~s}$ at room temperature and two extracts were collected into a new glass tube and filtered through glass wool. Wax extracts were evaporated under $\mathrm{N}_{2}$ and transferred into a 2-mL autosampler vials. Next, the extracts were evaporated completely and derivated in $20 \mu \mathrm{L}$ pyridine and $20 \mu \mathrm{L}$ bis-N,O-trimethylsilyltrifluoroacetamide (BSTFA) at $70^{\circ} \mathrm{C}$ for $45 \mathrm{~min}$. The samples were again dried under $\mathrm{N}_{2}$ and dissolved in $200 \mu \mathrm{L}$ of choloform for GC-MS analysis. Samples were injected into a DM-5 capillary column $(30 \mathrm{~m} \times 0.25 \mathrm{~mm} \times 0.2 \mu \mathrm{m})$ of 9790 gas chromatograph (FL9790, Zhejiang Fuli Analytical Instrument Co., Ltd., China) equipped with a flame ionization detector (FID). 
The carrier gas was nitrogen, the temperature of injector and FID were 300 and $320^{\circ} \mathrm{C}$, respectively. The GC oven was held at $80^{\circ} \mathrm{C}$ for $10 \mathrm{~min}$, heated at $15^{\circ} \mathrm{C} \mathrm{min}{ }^{-1}$ to $260^{\circ} \mathrm{C}$ and held for $10 \mathrm{~min}$. The temperature was then increased at $5^{\circ} \mathrm{C} \mathrm{min}^{-1}$ to $320^{\circ} \mathrm{C}$, where the temperature was held for $15 \mathrm{~min}$. Compounds identification was based on their retention time by a GCMS-QP2010 Ultra Mass Spectrometric Detector (Shimadzu, Kyoto, Japan). Cuticular wax quantification was based on the FID peak area as compared with the internal standard peak area.

Water loss measurement: For water loss measurement, faba bean leaves were dark acclimated for $12 \mathrm{~h}$ to ensure the stomatal closure, and then dipped into the distilled water for $1 \mathrm{~h}$ and then the saturated mass was measured. Next, the leaf samples were put into a dark chamber for continuous dehydration and weighed at 15-min intervals for $150 \mathrm{~min}$. Finally, faba bean leaves were dried in an oven at $70^{\circ} \mathrm{C}$ for $24 \mathrm{~h}$ and the dry mass was determined. The leaf water loss was calculated as follows: water loss [\%] = $(\mathrm{SM}-\mathrm{FM}) /(\mathrm{SM}-\mathrm{DM}) \times 100$.

Statistical analysis: The data were the average of four replicates. All statistical analyses were performed using SPSS 19.0. Two-way analysis of variance (ANOVA) was applied to analyze the effects of light wavelengths and drought stress on plant growth and physiological parameters. The effects of drought stress on these parameters under different light wavelengths were further analyzed using Student's $t$-test, with $P<0.05$ as the statistical significance threshold.

\section{Results}

Plant morphology: After one month growing under different light wavelengths, faba bean showed obvious morphological changes. The leaves of plants grown under red and yellow lights were smaller, curled and thick, whereas the leaves under blue and violet lights were flat and thin. The leaf size of plants grown under violet light was the same as under white light. After $15 \mathrm{~d}$ of water stress, plants began to wilt, plants grown under yellow and blue lights showed a lower wilting phenotype, but the leaves under violet light showed the most serious wilting phenotype.

Plant growth parameters: The two-way ANOVA analysis indicated that drought stress significantly influenced the height, stem diameter, and RWC of faba bean seedlings under all five light wavelengths, and significant interactions between water stress and light wavelengths were observed only on stem diameter (Table 1). Drought stress generally decreased the height of faba bean plants under all light wavelengths, but significant difference was only observed at yellow light when compared with the well-watered plants. Compared with the white light, four monochromatic lights all increased the faba bean height irrespective of water conditions. The stem diameter of plants grown at monochromatic lights was also lower than those at white light under well-watered condition. Drought stress also reduced the stem diameter of faba bean seedlings at all light wavelengths, except the ones at violet light. Drought stress significantly reduced the leaf area only at white light, and decreased the leaf RWC only at yellow light. Irrespective of water conditions, plants grown under red and yellow lights had higher RWC than the others.

Antioxidant enzymes, MDA, and insoluble protein content: The two-way ANOVA analysis showed that drought stress posed a significant influence on plant antioxidant enzymes activities and content of osmotics;

Table 1. Effects of drought stress on plant growth parameters under different light wavelengths. W, R, Y, B, V represent white, red, yellow, blue, and violet light, respectively. Data are the mean \pm SD from four replicates. ${ }^{*},{ }^{* *},{ }^{* * *}$ represent significant difference at $P<0.05, P<0.01$, and $P<0.001$, respectively. RWC - relative water content.

\begin{tabular}{llllll}
\hline Light & Treatment & Height $[\mathrm{cm}]$ & Stem diameter $[\mathrm{mm}]$ & Leaf area $\left[\mathrm{cm}^{2}\right]$ & RWC $[\%]$ \\
\hline $\mathrm{W}$ & Normal & $43.00 \pm 1.84$ & $4.33 \pm 0.25$ & $12.95 \pm 0.78$ & $72.81 \pm 2.11$ \\
& Drought & $39.75 \pm 1.03$ & $3.02 \pm 0.24^{* *}$ & $10.52 \pm 0.58^{*}$ & $70.71 \pm 1.00$ \\
$\mathrm{R}$ & Normal & $44.90 \pm 1.34$ & $3.79 \pm 0.22$ & $8.14 \pm 1.33$ & $80.90 \pm 0.46$ \\
& Drought & $41.50 \pm 1.63$ & $3.57 \pm 0.14$ & $7.92 \pm 0.19$ & $76.70 \pm 2.76$ \\
$\mathrm{Y}$ & Normal & $57.15 \pm 2.30$ & $3.92 \pm 0.27$ & $6.28 \pm 0.71$ & $82.24 \pm 2.06$ \\
& Drought & $48.95 \pm 1.24^{*}$ & $3.77 \pm 0.11$ & $8.43 \pm 1.83$ & $76.07 \pm 1.13^{*}$ \\
$\mathrm{~B}$ & Normal & $49.88 \pm 1.73$ & $3.64 \pm 0.18$ & $8.04 \pm 0.50$ & $75.93 \pm 3.42$ \\
& Drought & $44.25 \pm 1.90$ & $3.48 \pm 0.11$ & $8.03 \pm 0.63$ & $71.22 \pm 1.41$ \\
$\mathrm{~V}$ & Normal & $45.80 \pm 0.88$ & $3.61 \pm 0.33$ & $10.18 \pm 0.57$ & $76.27 \pm 1.66$ \\
& Drought & $42.98 \pm 2.10$ & $3.86 \pm 0.30$ & $8.98 \pm 0.23$ & $73.03 \pm 1.23$ \\
ANOVA analysis $(F)$ & & & & \\
Light $(\mathrm{L})$ & & $15.00^{* * *}$ & $0.42^{\mathrm{ns}}$ & $8.14^{* * *}$ & $5.80^{* * *}$ \\
Water $(\mathrm{W})$ & & $19.74^{* * *}$ & $4.88^{*}$ & $0.38^{\text {ns }}$ & $11.35^{* *}$ \\
L $\times$ W & & $0.93^{\text {ns }}$ & $3.32^{*}$ & $1.89^{\text {ns }}$ & $0.32^{\text {ns }}$ \\
\hline
\end{tabular}


light wavelengths also posed a significant influence on plant antioxidant enzyme activities, and significant interactions between water stress and light wavelengths were observed on CAT, GR, APX activities and MDA content (Table 2). Drought stress increased the SOD activity, but the significant difference was only observed at blue light, whereas generally decreased the activity of POD under all light wavelengths, with significant difference observed at violet light when compared with the well-watered plants. The effects of drought stress on CAT activity varied between different lights. Drought stress significantly increased the activity of CAT at white light, but significantly decreased the CAT activity at red and blue lights. Drought stress significantly increased the activity of GR at yellow light but decreased at blue light. Compared with the white light, four monochromatic lights all decreased the activity of APX under well-watered condition. However, drought stress increased the APX activity under monochromatic lights except for violet, but decreased the APX activity at white light. At yellow light, drought stress also significantly increased the MDA content. Moreover, drought stress also increased the content of soluble protein under all light wavelengths, but significant difference was only observed at blue light.

Photosynthesis parameters: Drought stress and light wavelengths imposed a significant influence on the photosynthetic performance of faba bean, and the significant interactions between water and light were observed for all photosynthesis parameters (Fig. 1; Table 1S, supplement). Under well-watered condition, the $P_{\mathrm{N}}$ and $g_{\mathrm{s}}$ at blue light were the highest and almost two times of those at white light, and plants grown under red and yellow light had lower $P_{\mathrm{N}}$ and $g_{\mathrm{s}}$. Drought stress significantly decreased the $P_{\mathrm{N}}$ under all light wavelengths except for red light, and the biggest decrease was observed at violet light, where the $P_{\mathrm{N}}$ of well-watered plants was 4.4 times of the droughtstressed plants. Drought stress dramatically decreased $g_{\mathrm{s}}$ by 79,78 , and $76 \%$ at violet, blue, and white lights, respectively. Drought stress also significantly reduced the $C_{\mathrm{i}}$ except for violet light. Moreover, drought stress significantly decreased the $E$ of faba bean leaves under all light wavelengths, and the biggest decrease $(66 \%)$ and smallest decrease $(40 \%)$ were observed at violet and red lights, respectively.

Cuticular wax composition: The two-way $A N O V A$ analysis showed that drought stress significantly influenced the cuticular wax deposition except for alkane content. Light imposed a significant effect on all cuticular wax compounds, and significant interactions between light and drought stress were observed on all wax compound depositions (Table 1S). Under well-watered conditions, monochromatic lights increased the cuticular wax load except for violet light, when compared with that at white light (Fig. 2). The total wax coverage ranged from $0.61 \mu \mathrm{g} \mathrm{cm}^{-2}$ (violet) to $1.97 \mu \mathrm{g} \mathrm{cm}^{-2}$ (yellow), and except for violet light, other monochromatic lights increased the total wax coverage. The responses of total cuticular wax load on faba bean leaves to drought stress differed between

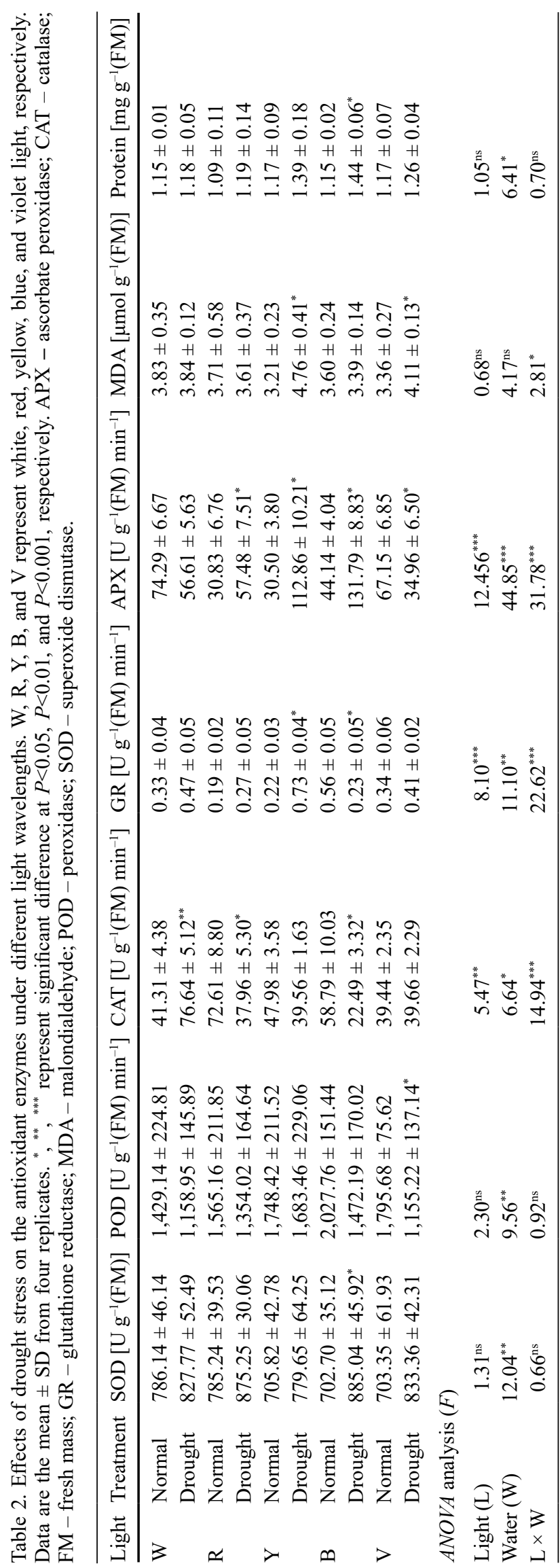


the five light wavelengths. Drought stress significantly increased total wax coverage by $47.4 \%$ at violet light, but decreased total wax load by 39.8 and $35.6 \%$ at blue and yellow lights, respectively. No significant difference was observed between two water conditions at white and red lights. The total wax loads decreased by 39.8 and $35.6 \%$ at blue and yellow lights under drought stress conditions, respectively.

Four different classes of compounds were identified within wax mixtures, including fatty acids, primary alcohols, alkanes, and alkylresorcinols (Fig. 3). Primary alcohols ( $c a .50 .1 \%$ ) dominated the wax mixtures at all light treatments under well-watered condition, followed by alkanes ( $c a .27 .0 \%$ ), fatty acids ( $c a .4 .4 \%$ ), and alkylresorcinols ( $c a .1 .8 \%$ ). Under well-watered conditions, the responses of the contents of primary alcohols and alkanes to different light wavelengths were similar to total wax coverage. However, drought stress changed the wax dominant compounds under specific light wavelengths. For example, the dominant wax compound at white and blue light turned to alkanes. Moreover, the effects of drought stress on different wax compounds coverage differed between light wavelengths. Drought stress significantly increased the content of alkanes by 80.5 and $80.5 \%$ at white and violet lights, respectively, but significantly decreased the contents of primary alcohols by 41.9 and $65.6 \%$ at yellow and blue lights, respectively, when compared with well-watered plants. In addition, drought stress also significantly reduced the contents of fatty acids at blue light and alkanes at yellow light. At red light, drought stress significantly increased the fatty acids content by $132.1 \%$.

The chain length of fatty acids ranged from $\mathrm{C}_{24}$ to $\mathrm{C}_{28}, \mathrm{C}_{26}$ was the dominant compound (56.8 and 55.3\% under well-watered and drought conditions, respectively) (Fig. 2S, supplement). Drought stress had no effect on the relative abundance of fatty acids at white and violet lights. Drought stress significantly decreased the relative abundance of $\mathrm{C}_{24}$ by 17.8 and $33.0 \%$ at yellow and blue lights, respectively. At blue light, drought stress significantly increased the relative abundance of $\mathrm{C}_{28}$ by 44.7\%. Primary alcohols consisted of both even and odd carbon number with chain length ranging from $\mathrm{C}_{24}$ to $\mathrm{C}_{34}$, which exhibited significant odd/even predominance with the relative abundance of even carbon numbers reached up to 90.7 and $91.2 \%$ under well-watered and drought conditions, respectively (Fig. 3S, supplement). Light wavelengths imposed a certain effect on the carbon chain distribution of primary alcohol. No primary alcohols with $\mathrm{C}_{30}$ to $\mathrm{C}_{34}$ were detected at yellow and violet lights. The content of odd-numbered primary alcohols was too low to be detected at blue, red, and violet lights. $\mathrm{C}_{26}$ alcohol was the most abundant under both water conditions. Drought stress significantly increased $\mathrm{C}_{26}$ abundance to $65.2 \%$ at blue light. Drought stress had no influence on the relative abundance of $\mathrm{C}_{26}$ alcohols at other lights. At white light, drought stress significantly decreased the relative abundance of $\mathrm{C}_{24}, \mathrm{C}_{25}$, and $\mathrm{C}_{28}$ alcohols, but significantly increased the relative abundance of $\mathrm{C}_{27}$ and $\mathrm{C}_{34}$ alcohols. Drought stress had similar effects on the carbon chain

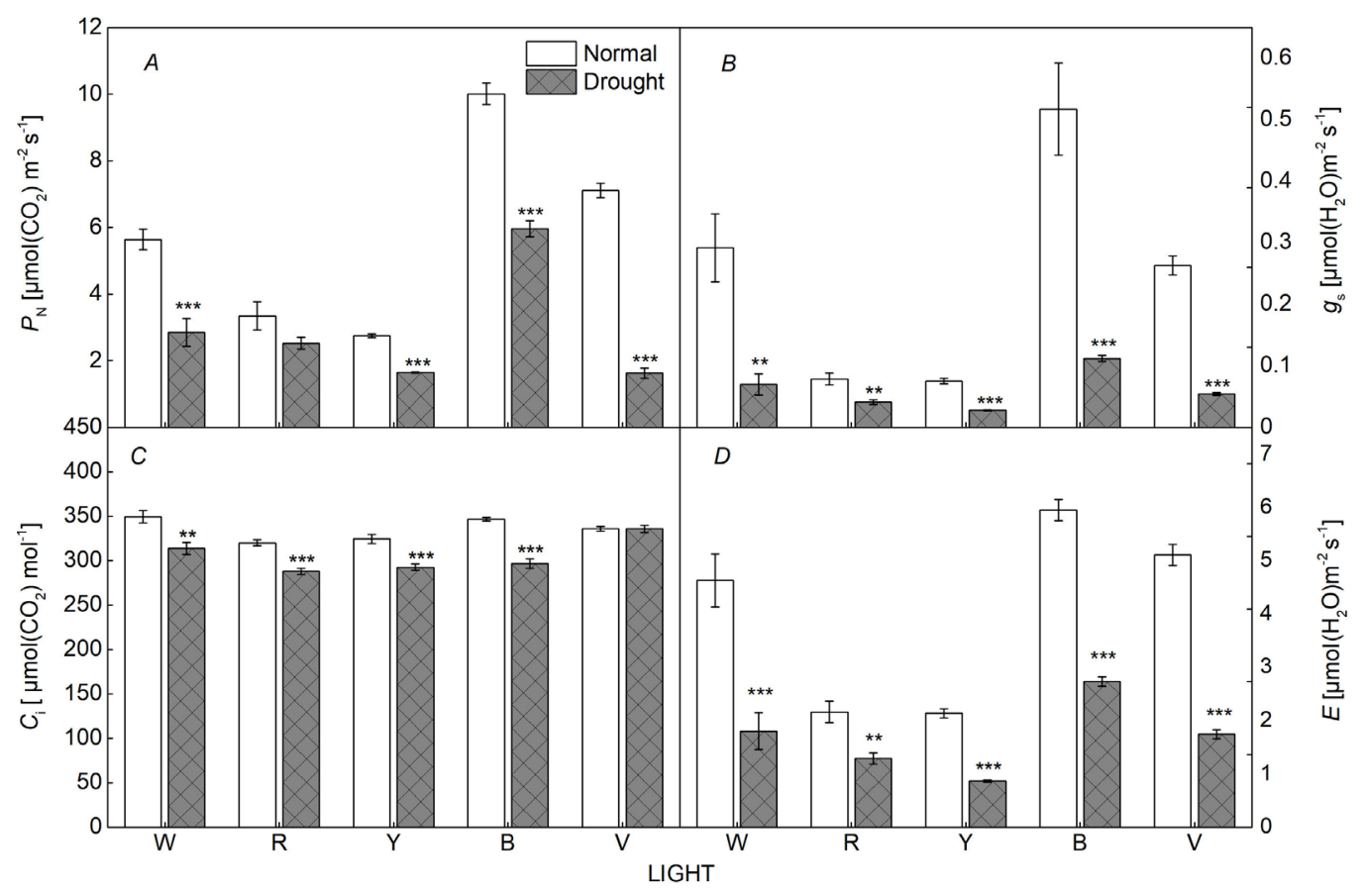

Fig. 1. Effect of drought stress on the photosynthesis parameters of faba bean under different light wavelengths: net photosynthetic rate $\left(P_{\mathrm{N}}\right)(A)$, stomatal conductance $\left(g_{\mathrm{s}}\right)(B)$, intercellular $\mathrm{CO}_{2}$ concentration $\left(C_{\mathrm{i}}\right)(C)$, transpiration rate $(E)(D)$. W, $\mathrm{R}, \mathrm{B}, \mathrm{Y}$, and $\mathrm{V}$ represent white, red, yellow, blue, and violet light, respectively. Each data were the mean of four replications. The error bar represents standard error. ${ }^{*},{ }^{* *},{ }^{* * *}$ represent significant difference at $P<0.05, P<0.01$, and $P<0.001$, respectively. 


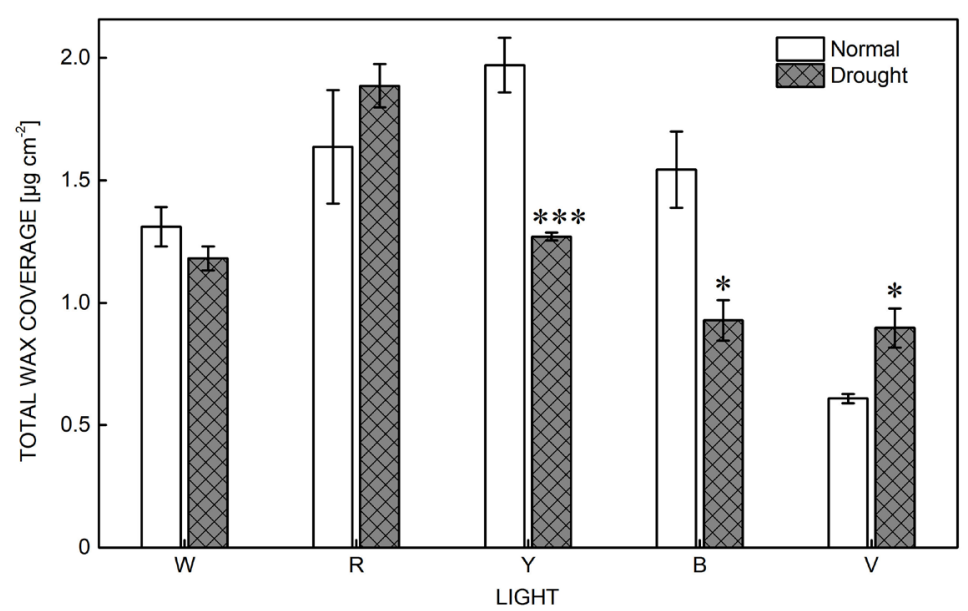

Fig. 2. Effect of drought stress on the total wax coverage of faba bean leaves under different light wavelengths. $\mathrm{W}, \mathrm{R}, \mathrm{Y}, \mathrm{B}$, and $\mathrm{V}$ represent white, red, yellow, blue, and violet light, respectively. Each data were the mean of four replications. The error bar represents standard error. ${ }^{*},{ }^{* *},{ }^{* * *}$ represent significant difference at $P<0.05$, $P<0.01$, and $P<0.001$, respectively.

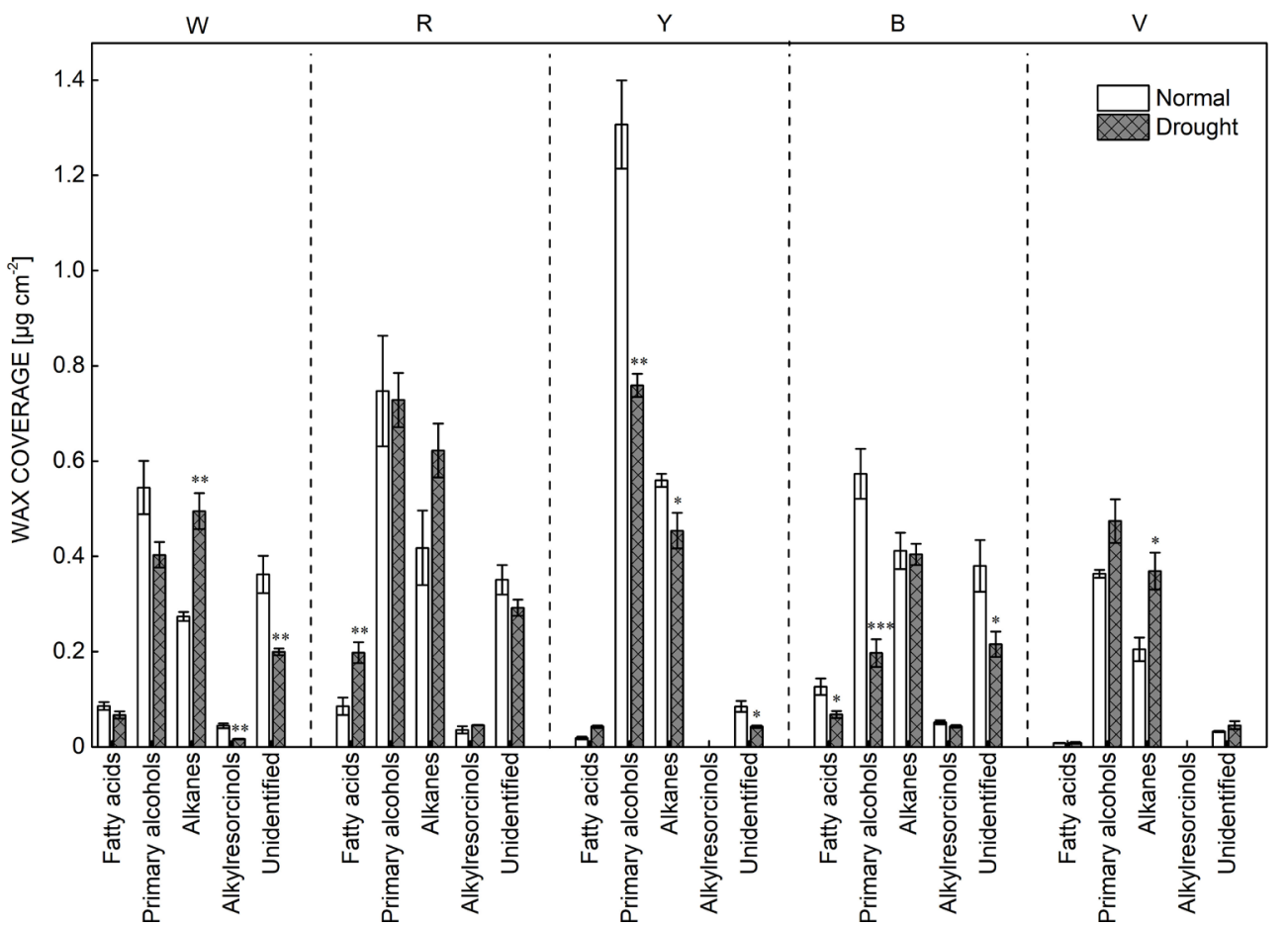

Fig. 3. Effects of drought stress on cuticular wax composition and contents of faba bean leaves under different light wavelengths. W, R, Y, $\mathrm{B}$, and $\mathrm{V}$ represent white, red, yellow, blue, and violet light, respectively. Each data were the mean of four replications. The error bar represents standard error. ${ }^{*},{ }^{* *},{ }^{* * *}$ represent significant difference at $P<0.05, P<0.01$, and $P<0.001$, respectively. length distribution of primary alcohols at red and yellow lights, with the relative abundance of even-numbered alcohols decreased and odd-numbered alcohols increased. At blue and violet lights, drought stress significantly decreased the relative abundance of $\mathrm{C}_{25}$ alcohol, which was even undetectable at blue light.

A broad range of alkanes with $\mathrm{C}_{25}$ to $\mathrm{C}_{33}$ chain length was detected in faba bean wax, dominated by $\mathrm{C}_{31}$ alkanes (Fig. 4S, supplement). $\mathrm{C}_{25}, \mathrm{C}_{27}$, and $\mathrm{C}_{28}$ alkanes were not detectable at white, red, and blue lights. Drought stress significantly decreased the $\mathrm{C}_{30}$ alkane abundance at white, red, and blue lights. At red and blue lights, drought stress significantly increased the relative abundance of $\mathrm{C}_{26}$ alkanes. Drought stress increased the relative abundance of $\mathrm{C}_{31}$ at all light wavelengths except for blue light, and the significant difference was only observed at red light. $\mathrm{C}_{33}$ alkanes were the second most abundant compound, with its relative abundance around $30 \%$. At white light, $\mathrm{C}_{33}$ alkanes abundance significantly decreased by $6.9 \%$ by drought stress, when compared with well-watered plants.

Water loss: We also measured the water loss of faba bean leaves under well-watered and drought stress conditions to test the ecophysiological function of cuticular wax (Fig. 4). Under well-watered condition, plants had the lowest water loss at red light and had the highest water loss at yellow light. Drought stress increased the water loss of red lightgrown plants, but reduced the water loss of plants grown under blue and yellow lights. The correlation analysis between water loss and wax compositions also indicated that leaf water loss at 15 and 30 min was positively correlated with total wax load and primary alcohols content (Table 3 ). The lower water loss at blue and yellow lights was induced by the significantly decreased total wax 


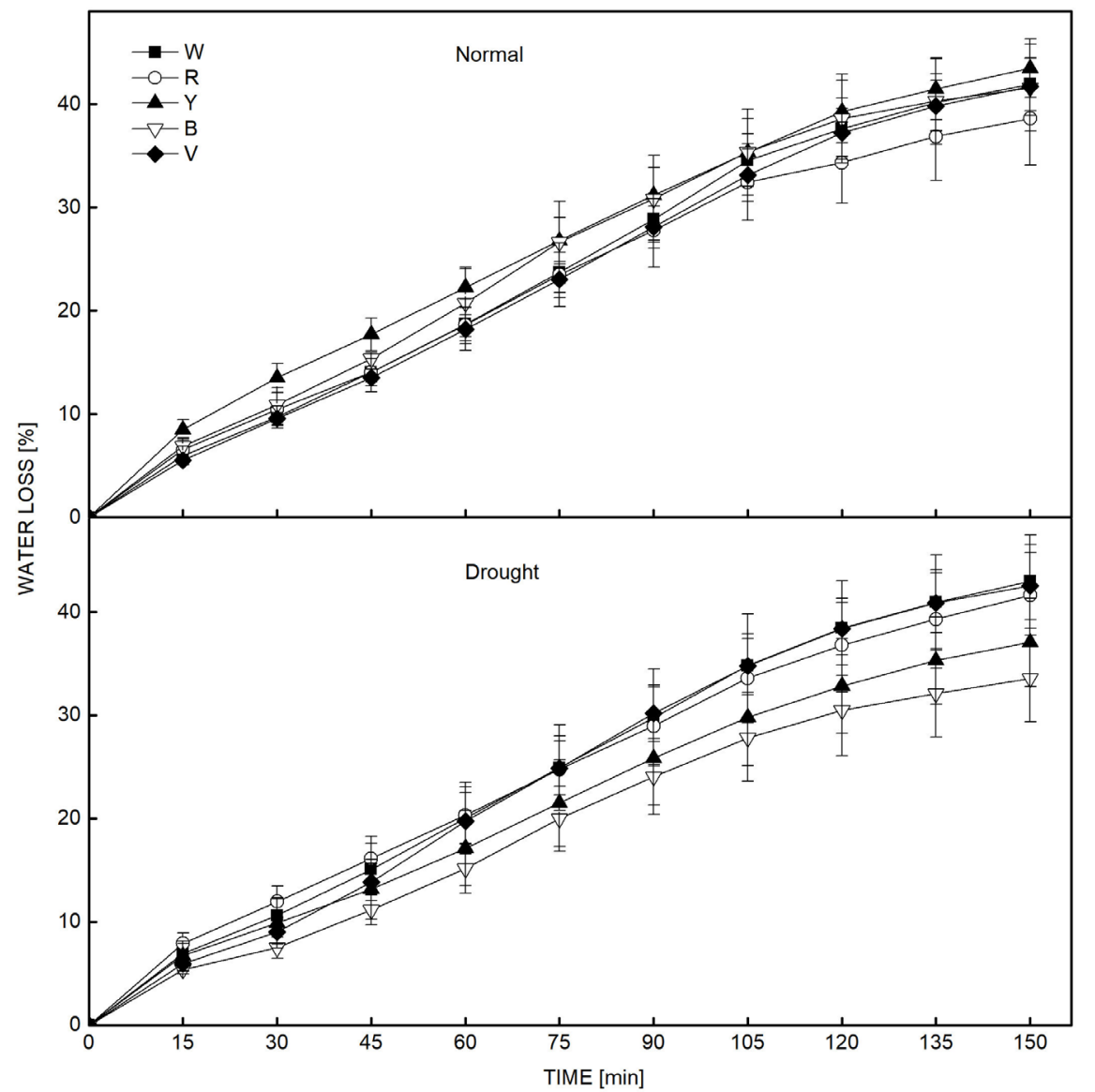

Fig. 4. Effect of drought stress on the water loss rate of faba bean leaves under different light wavelengths. W, R, Y, $\mathrm{B}$, and $\mathrm{V}$ represent white, red, yellow, blue, and violet light, respectively. Each data were the mean of four replications. The error bar represents standard error. load and primary alcohols content under drought stress. And the higher total wax load of plants grown under red light induced the increase of water loss.

\section{Discussion}

Modifications in the light spectrum strongly influenced the plant growth and morphogenesis of faba bean. Under wellwatered condition, all monochromatic lights increased the plant height but decreased the stem diameter and leaf area. This implied that, when compared with the full length white light, the quality of the monochromatic lights might be poor and not sufficient for the requirements of normal plant growth (Smith 1994, 2000; Kurepin et al. 2007), and normal plant growth and development need the synergistic effect of more than one photoreceptor (Usami et al. 2004). Drought stress significantly decreased the stem diameter and leaf area at white light. This was consistent with morphological adaptations of plants which possess a small leaf size to withstand the water deficit (Sinclair and Muchow 2001). Under drought-stress conditions, the leaf RWC plays an important role in maintaining osmotic equilibrium through the accumulation of osmotic protectants (Siddiqui et al. 2015). In this study, plant grown under red and yellow lights were succulent and pretreatment with red or yellow LED light resulted in increased RWC and thus the plant resistance to water deficit.
We also found that light spectra imposed a direct influence on plant antioxidant defense system. Plants growing under red LED light resulted in higher activities of SOD and CAT under well-watered condition, when compared to other light spectra. This was consistent with the results of a study of Samuoliene et al. (2012a) who reported that red LED light, when used alone or applied as a supplementary light with natural illumination, activated the antioxidant defense system, enhanced antioxidant capacity, and increased the contents of phenolic compounds and alpha tocopherol. Limited water supply induced the overproduction of ROS (including ${ }^{1} \mathrm{O}_{2}, \mathrm{H}_{2} \mathrm{O}_{2}$, $\mathrm{O}_{2}^{-}$, and $\mathrm{HO}$ ), and promoted oxidative damaging to DNA, proteins, and lipids (Miller et al. 2010). In this study, drought stress significantly increased the MDA content of plants grown under yellow and violet lights. ROS act as signaling molecules for stress responses and plant have evolved enzymatic or nonenzymatic mechanisms to avoid oxidative stresses (Singh et al. 2011). Osmotic adjustment and antioxidant defense system are the major physiological adaptations of plants under drought.

Drought stress dramatically increased the activities of GR and APX under yellow light. Plants pretreated with blue LED light presented significantly higher SOD and APX activities. Drought stress also significantly increased the activity of APX under red light. These results showed that plants grown under drought conditions possessed high activities of enzymes involved in the ascorbate-glutathione 


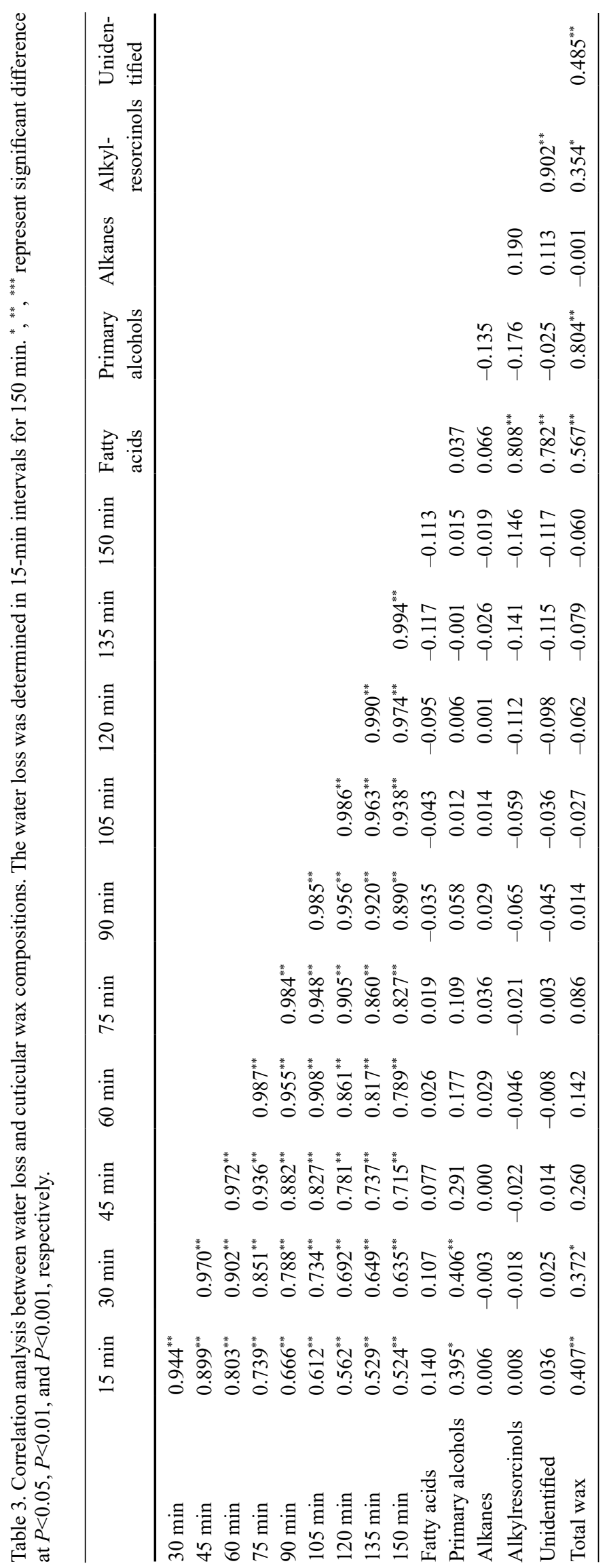


cycle, like APX, which was the most important peroxidase in $\mathrm{H}_{2} \mathrm{O}_{2}$ detoxification (Scheibe and Beck 2011). The dramatic increase of APX activity observed in plants grown at blue and yellow lights under drought stress might contribute to the increased APX gene expression, and previous study also showed that APX plays an important role in plant stress responses (Jardim-Messeder et al. 2018). In addition, the APX gene expression and activity in chloroplasts has an important role regulating stomatal closure and photosynthetic activity (Danna et al. 2003, Caverzan et al. 2014). Plants pretreated with blue LED light also had higher soluble protein content under drought stress, the increase of osmoprotectants was vital for the maintenance of cell turgor. This was consistent with the results from other studies on lettuce (Zhang et al. 2018) and cucumber (Wang et al. 2009).

Light spectrum is an important factor affecting plant photosynthesis capacity. The effects of monochromatic lights on photosynthetic performance are mainly associated with the stimulation of proper photoreceptors (Landi et al. 2020). In this study, plants pretreated with pure red light presented lower photosynthesis capacity than those under white light, indicating that sole red light is not sufficient for plant normal growth. This might be attributed to the impairment of plant growth (such as elongated stem and smaller leaf area), unresponsive stomata, and low chlorophyll and carotenoid content (Hogewoning et al. 2010). Blue light is effective for plants to prevent any overt dysfunctional photosynthesis; the light-saturated assimilation, leaf mass per unit leaf area and chlorophyll content display clear progressive trends with increasing blue light percentage in the range of $0-50 \%$ (Hogewoning et al. 2010), and this was validated by the highest photosynthetic rate in plants grown under blue light in this study. Blue light when applied as a supplementary light significantly increased photosynthetic capacity in tomato, cucumber, and pepper (Ménard et al. 2005, Samuolienè et al. 2012b). The stimulation effect of stomatal conductance driven by blue light is of great importance for improving net photosynthesis. Stomatal opening posed a direct influence on stomatal water loss and drought adaptation. In this study, drought stress significantly decreased the stomatal conductance in plants pretreated with monochromatic lights. For example, higher reductions in stomatal conductance were observed at violet, blue, and white lights. Reduction of transpiration rate induced by drought stress was consistent with stomatal conductance. The biggest and smallest decrease of transpiration rate was observed at violet and red lights, which was in accordance with the larger and smaller photosynthesis capture area (leaf area) at violet and red lights. Liu et al. (2018) also reported that cucumber plants grown at violet and blue lights had higher stomatal conductance when compared with plants grown at red light.

In our study, light spectra posed a significant influence on total wax coverage on faba bean leaves. Plants grown under red and yellow lights had higher total wax load than plants grown under blue and violet lights. This might be attributed to the differentially expressed waxy genes induced by various light spectra (Go et al. 2014).
Light spectrum also influenced the contents of individual compounds in wax mixture. No alkylresorcinols were detected in plants grown under yellow and violet lights, implying that the biosynthesis of these compounds might be limited, particularly under yellow and violet lights. Our previous study also confirmed that the variation of wax chemical compositions under monochromatic lights was driven by the differentially waxy genes expression which involved in different wax biosynthesis pathways (unpublished). Light spectrum also influenced the carbon chain length distribution. For example, no primary alcohols with $\mathrm{C}_{30}$ to $\mathrm{C}_{34}$ were identified in plants grown under yellow and violet lights, and odd-numbered primary alcohols were too low to be detected under blue, red, and violet lights. Such change in the chemical properties of cuticular wax resulted in the change of cuticle transpiration, which could be reflected by the varied leaf water loss under two water conditions. The correlation analysis between wax compositions and water loss showed that water loss was positively correlated to total wax load and primary alcohols content. Our study also showed that plants grown at yellow lights had the biggest water loss and the highest total wax coverage under well-watered condition, when compared with other lights. The significantly decreased total wax load of plants grown at yellow and blue lights under drought stress conditions was accompanied by the lower water loss, whereas the increased wax composition of plants grown at red light induced the increased water loss under drought stress. This was inconsistent with some studies which demonstrated that higher wax content was responsible for drought tolerance (Kerstiens 1996). However, some studies also reported that there was no correlation between wax deposition and cuticle water loss (Shepherd and Wynne Griffiths 2006). The dominant wax compound in plants grown under blue light changed from primary alcohols to alkanes under drought stress, this was validated by previous studies that a specific increase of alkane content in Arabidopsis contributed to the greater drought tolerance (Le Provost et al. 2013), and leaf $n$-alkanes distribution have sometimes been related to changing environmental conditions (Liu et al. 2017). In addition, the changes of wax compound chain length distribution could affect the polarity and then imposed some influence on cuticle transpiration rates (Bringe et al. 2006). In our study, the lower water loss in plants under yellow light was accompanied by the increased $C_{31}$ to $C_{33}$ alkane abundance under drought stress, confirming the importance of specific alkanes in improving plant drought resistance.

Overall, specific light-mediated acclimations at plant and leaf level reduced the vulnerability of faba bean plants to drought stress. Cultivating plants in greenhouse or growth chamber with specific light wavelengths or light combination can be considered as a potential method to increase subsequent stress tolerance. Pretreatment of lemon balm plants with red + blue LEDs $(70: 30 \%)$ could improve their growth and quality under drought stress (Ahmadi et al. 2019). The combination of red and blue LEDs (ratio of red and blue light 3:1) also could improve the tolerance of melon seeds to powdery mildew by 
enhancing sucrose metabolism and increasing lignin accumulation (Jing et al. 2018). Though we did not test the efficiency of light combinations of different wavelengths, faba bean plants treated with blue + yellow LEDs might enhance their drought tolerance by reducing stomatal water loss and regulating cuticle transpiration. However, detailed light ratio and intensity between light wavelengths need further investigation in the future.

Conclusions: This study revealed that faba bean plants exposed to specific LED wavelengths showed different defense strategies against subsequent water stress. We concluded that plants grown under blue and yellow lights showed better drought tolerance than that under other light wavelengths. Blue light improved the photosynthesis capacity, antioxidant enzymes activities, and the leaf cuticle transpiration by mediating cuticular wax chemical properties under drought conditions. The dominant wax component of plants grown at blue light changed from primary alcohols under well-watered condition to alkanes under drought stress. Yellow light also played a positive role in reducing nonstomatal water loss under drought stress by decreasing total wax coverage, primary alcohols content, and increased $\mathrm{C}_{31}-\mathrm{C}_{33}$ alkanes abundance. Red and violet lights had no positive effect on the restriction of stomatal and nonstomatal water loss under drought stress. Our study, for the first time, clarified the effects of specific light wavelengths on drought stress resistance through altering cuticular wax deposition and physiological responses. Further studies are needed to clarify the influence of specific light wavelengths (particularly blue and yellow lights) on crop yield and quality and the combination effect of different light wavelengths in modern facility agriculture.

\section{References}

Aebi H.: Catalase in vitro. - Method. Enzymol. 105: 121-126, 1984.

Ahmadi T., Shabani L., Sabzalian M.R.: Improvement in drought tolerance of lemon balm, Melissa officinalis L. under the pre-treatment of LED lighting. - Plant Physiol. Bioch. 139: 548-557, 2019.

Bi H., Kovalchuk N., Langridge P. et al.: The impact of drought on wheat leaf cuticle properties. - BMC Plant Biol. 17: 85, 2017.

Bourget C.M.: An introduction to light-emitting diodes. HortScience 43: 1944-1946, 2008.

Bradford M.M.: A rapid and sensitive method for the quantitation of microgram quantities of protein utilizing the principle of protein-dye binding. - Anal. Biochem. 72: 248-254, 1976.

Bringe K., Schumacher C.F., Schmitz-Eiberger M. et al.: Ontogenetic variation in chemical and physical characteristics of adaxial apple leaf surfaces. - Phytochemistry 67: 161-170, 2006.

Buschhaus C., Jetter R.: Composition and physiological function of the wax layers coating Arabidopsis leaves: $\beta$-amyrin negatively affects the intracuticular water barrier. - Plant Physiol. 160: 1120-1129, 2012.

Caverzan A., Bonifacio A., Carvalho F.E.L. et al.: The knockdown of chloroplastic ascorbate peroxidases reveals its regulatory role in the photosynthesis and protection under photo-oxidative stress in rice. - Plant Sci. 214: 74-87, 2014.

Chance B., Maehly A.C.: Assay of catalases and peroxidases. Method. Enzymol. 136: 764-775, 1955.

Choi H.G., Moon B.Y., Kang N.J.: Effects of LED light on the production of strawberry during cultivation in a plastic greenhouse and in a growth chamber. - Sci. Hortic.Amsterdam 189: 22-31, 2015.

Danna C.H., Bartoli C.G., Sacco F. et al.: Thylakoid-bound ascorbate peroxidase mutant exhibits impaired electron transport and photosynthetic activity. - Plant Physiol. 132: 2116-2125, 2003.

de Wit M., Galvão V.C., Fankhauser C.: Light-mediated hormonal regulation of plant growth and development. - Annu. Rev. Plant Biol. 67: 513-537, 2016.

Dhindsa R.S., Plumb-Dhindsa P., Thorpe T.A.: Leaf senescence: correlated with increased levels of membrane permeability and lipid peroxidation, and decreased levels of superoxide dismutase and catalase. - J. Exp. Bot. 32: 93-101, 1981.

Farooq M., Wahid A., Kobayashi N. et al.: Plant drought stress: effects, mechanisms and management. - Agron. Sustain. Dev. 29: $185-212,2009$.

Giannopolitis C.N., Ries S.K.: Superoxide dismutases: I. Occurrence in higher plants. - Plant Physiol. 59: 309-314, 1977.

Giese B.N.: Effects of light and temperature on the composition of epicuticular wax of barley leaves. - Phytochemistry 14: 921-929, 1975.

Go Y.S., Kim H., Kim H.J., Suh M.C.: Arabidopsis cuticular wax biosynthesis is negatively regulated by the DEWAX gene encoding an AP2/ERF-type transcription factor. - Plant Cell 26: 1666-1680, 2014.

Guo Y., Busta L., Jetter R.: Cuticular wax coverage and composition differ among organs of Taraxacum officinale. Plant Physiol. Bioch. 115: 372-379, 2017.

Guo Y., Jetter R.: Comparative analyses of cuticular waxes on various organs of potato (Solanum tuberosum L.). - J. Agr. Food Chem. 65: 3926-3933, 2017.

Halliwell B., Foyer C.: Properties and physiological function of a glutathione reductase purified from spinach leaves by affinity chromatography. - Planta 139: 9-17, 1978.

Hatterman-Valenti H., Pitty A., Owen M.: Environmental effects on velvetleaf (Abutilon theophrasti) epicuticular wax deposition and herbicide absorption. - Weed Sci. 59: 14-21, 2011.

Hogewoning S.W., Trouwborst G., Maljaars H. et al.: Blue light dose-responses of leaf photosynthesis, morphology, and chemical composition of Cucumis sativus grown under different combinations of red and blue light. - J. Exp. Bot. 61: 3107-3117, 2010

Hooker T.S., Millar A.A., Kunst L.: Significance of the expression of the CER6 condensing enzyme for cuticular wax production in Arabidopsis. - Plant Physiol. 129: 1568-1580, 2002.

Hussain M., Malik M.A., Farooq M. et al.: Improving drought tolerance by exogenous application of glycinebetaine and salicylic acid in sunflower. - J. Agron. Crop Sci. 194: 193199, 2008.

Jardim-Messeder D., Caverzan A., Rauber R. et al.: Thylakoidal APX modulates hydrogen peroxide content and stomatal closure in rice (Oryza sativa L.). - Environ. Exp. Bot. 150: 46-56, 2018

Jetter R., Kunst L., Samuels A.L.: Composition of plant cuticular waxes. - In: Riederer M., Müller C. (ed.): Biology of the Plant Cuticle. Pp. 145-181. Blackwell Publishing, Oxford 2008.

Jing X., Wang H., Gong B. et al.: Secondary and sucrose metabolism regulated by different light quality combination involved in melon tolerance to powdery mildew. - Plant 
Physiol. Bioch. 124: 77-87, 2018.

Kerstiens G.: Cuticular water permeability and its physiological significance. - J. Exp. Bot. 47: 1813-1832, 1996.

Kim K., Kook H.S., Jang Y.J. et al.: The effect of blue-lightemitting diodes on antioxidant properties and resistance to Botrytis cinerea in tomato. - J. Plant Pathol. Microb. 4: 203, 2013.

Kumar A., Panda D., Biswal M. et al.: Low light stress influences resistant starch content and glycemic index of rice $(O$. sativa L.). - Starch 71: 1800216, 2019.

Kurepin L.V., Walton L.J., Reid D.M.: Interaction of red to far red light ratio and ethylene in regulating stem elongation of Helianthus annuus. - Plant Growth Regul. 51: 53-61, 2007.

Landi M., Zivcak M., Sytar O. et al.: Plasticity of photosynthetic processes and the accumulation of secondary metabolites in plants in response to monochromatic light environments: A review. - BBA-Bioenergetics 1861: 148131, 2020.

Lee S.B., Kim H., Kim R.J., Suh M.C.: Overexpression of Arabidopsis MYB96 confers drought resistance in Camelina sativa via cuticular wax accumulation. - Plant Cell Rep. 33: 1535-1546, 2014.

Lei Y., Yin C., Li C.: Differences in some morphological, physiological, and biochemical responses to drought stress in two contrasting populations of Populus przewalskii. Physiol. Plantarum 127: 182-191, 2006.

Le Provost G., Domergue F., Lalanne C. et al.: Soil water stress affects both cuticular wax content and cuticle-related gene expression in young saplings of maritime pine (Pinus pinaster Ait). - BMC Plant Biol. 13: 95, 2013.

Li H., Guo Y., Cui Q. et al.: Alkanes (C29 and C31)-mediated intracuticular wax accumulation contributes to melatoninand ABA-induced drought tolerance in watermelon. - J. Plant Growth Regul., 2020. doi.org/10.1007/s00344-020-10099-z

Li L., Du Y., He C. et al.: Maize glossy6 is involved in cuticular wax deposition and drought tolerance. - J. Exp. Bot. 70: 3089-3099, 2019.

Li R.J., Li L.M., Liu X.L. et al:: Diurnal regulation of plant epidermal wax synthesis through antagonistic roles of the transcription factors SPL9 and DEWAX. - Plant Cell 31: 2711-2733, 2019.

Li Z., Li J., Du C. et al.: [Simultaneous measurement of five antioxidant enzyme activities using a single extraction system.] - J. Yunnan Normal Univ. 22: 44-48, 2002. [In Chinese] doi:10.3969/j.issn.1007-9793.2002.06.011

Liu H., Fu Y., Hu D. et al.: Effect of green, yellow and purple radiation on biomass, photosynthesis, morphology and soluble sugar content of leafy lettuce via spectral wavebands "knock out". - Sci. Hortic.-Amsterdam 236: 10-17, 2018.

Liu X., Feakins S.J., Dong X. et al.: Experimental study of leaf wax $n$-alkane response in winter wheat cultivars to drought conditions. - Org. Geochem. 113: 210-223, 2017.

Ma J., Pang B., Wang X. et al.: [The identification and appraisal use of broad bean seed quality in Jiangsu province.] J. Nanjing Agric. Technol. College 18: 13-16, 2002. [In Chinese] doi:10.3969/j.issn.1672-755X.2002.02.003

Macey M.: The effect of light on wax synthesis in leaves of Brassica oleracea. - Phytochemistry 9: 757-761, 1970.

Manivannan P., Jaleel C.A., Somasundaram R., Panneerselvam R.: Osmoregulation and antioxidant metabolism in droughtstressed Helianthus annuus under triadimefon drenching. C. R. Biol. 331: 418-425, 2008.

Medrano H., Escalona J.M., Bota J. et al.: Regulation of photosynthesis of $\mathrm{C}_{3}$ plants in response to progressive drought: Stomatal conductance as reference parameter. - Ann. Bot.-London 89: 895-905, 2002.

Ménard C., Dorais M., Hovi T., Gosselin A.: Developmental and physiological responses of tomato and cucumber to additional blue light. - Acta Hortic. 711: 291-296, 2005.

Miller G., Suzuki N., Ciftci-Yilmaz S., Mittler R.: Reactive oxygen species homeostasis and signalling during drought and salinity stresses. - Plant Cell Environ. 33: 453-467, 2010.

Morrow R.C.: LED lighting in horticulture. - HortScience 43: 1947-1950, 2008.

Olle M., Viršile A.: The effects of light-emitting diode lighting on greenhouse plant growth and quality. - Agr. Food Sci. Finland 22: 223-234, 2013.

Ouedraogo M., Hubac C.: Effect of far red light on drought resistance of cotton. - Plant Cell Physiol. 23: 1297-1303, 1982.

Ozkur O., Ozdemir F., Bor M., Turkan I.: Physiochemical and antioxidant responses of the perennial xerophyte Capparis ovata Desf. to drought. - Environ. Exp. Bot. 66: 487-492, 2009.

Panikashvili D., Savaldi-Goldstein S., Mandel T. et al.: The Arabidopsis DESPERADO/AtWBC11 transporter is required for cutin and wax secretion. - Plant Physiol. 145: 1345-1360, 2007.

Parsons E.P., Popopvsky S., Lohrey G.T. et al.: Fruit cuticle lipid composition and fruit post-harvest water loss in an advanced backcross generation of pepper (Capsicum sp.). - Physiol. Plantarum 146: 15-25, 2012.

Patwari P., Salewski V., Gutbrod K. et al.: Surface wax esters contribute to drought tolerance in Arabidopsis. - Plant J. 98: 727-744, 2019.

Randhir R., Shetty K.: Light-mediated fava bean (Vicia faba) response to phytochemical and protein elicitors and consequences on nutraceutical enhancement and seed vigour. - Process Biochem. 38: 945-952, 2003.

Raven J.A., Edwards D.: Physiological evolution of lower embryophytes: adaptations to the terrestrial environment. In: Hemsley A.R., Poole I. (ed.): The Evolution of Plant Physiology. Pp. 17-41. Elsevier Academic Press, London 2004.

Reid D., Tukey J.: Light intensity and temperature effects on epicuticular wax morphology and internal cuticle ultrastructure of carnations and Brussels sprouts leaf cuticles. J. Am. Soc. Hortic. Sci. 107: 417-420, 1982.

Riederer M., Schreiber L.: Protecting against water loss: analysis of the barrier properties of plant cuticles. - J. Exp. Bot. 52: 2023-2032, 2001.

Ristic Z., Jenks M.A.: Leaf cuticle and water loss in maize lines differing in dehydration avoidance. - J. Plant Physiol. 159: 645-651, 2002.

Roberts M.R., Paul N.D.: Seduced by the dark side: integrating molecular and ecological perspectives on the influence of light on plant defence against pests and pathogens. - New Phytol. 170: 677-699, 2006.

Samuolienè G., Brazaityte A., Duchovskis P. et al.: Cultivation of vegetable transplants using solid-state lamps for the shortwavelength supplementary lighting in greenhouses. - Acta Hortic. 952: 885-892, 2012b.

Samuolienė G., Sirtautas R., Brazaitytė A. et al.: Supplementary red-LED lighting and the changes in phytochemical content of two baby leaf lettuce varieties during three seasons. J. Food Agric. Environ. 10: 701-706, 2012a.

Scandalios J.: Oxidative stress: molecular perception and transduction of signals triggering antioxidant gene defenses. Braz. J. Med. Biol. Res. 38: 995-1014, 2005.

Scheibe R., Beck E.: Drought, desiccation, and oxidative stress. In: Lüttge U., Beck E., Bartels D. (ed.): Plant Desiccation Tolerance. Pp. 209-231. Springer, Berlin-Heidelberg 2011.

Schiedek D., Sundelin B., Readman J.W., Macdonald R.W.: 
Interactions between climate change and contaminants. Mar. Pollut. Bull. 54: 1845-1856, 2007.

Shepherd T., Robertson G., Griffiths D. et al.: Effects of environment on the composition of epicuticular wax from kale and swede. - Phytochemistry 40: 407-417, 1995.

Shepherd T., Wynne Griffiths D.: The effects of stress on plant cuticular waxes. - New Phytol. 171: 469-499, 2006.

Siddiqui M.H., Al-Khaishany M.Y., Al-Qutami M.A. et al.: Response of different genotypes of faba bean plant to drought stress. - Int. J. Mol. Sci. 16: 10214-10227, 2015.

Sinclair T.R., Muchow R.C.: System analysis of plant traits to increase grain yield on limited water supplies. - Agron. J. 93: 263-270, 2001

Singh L.P., Gill S.S., Tuteja N.: Unraveling the role of fungal symbionts in plant abiotic stress tolerance. - Plant Signal. Behav. 6: 175-191, 2011.

Singh S., Kumari R., Agrawal M., Agrawal S.B.: Differential response of radish plants to supplemental ultraviolet-B radiation under varying NPK levels: chlorophyll fluorescence, gas exchange and antioxidants. - Physiol. Plantarum 145: 474-484, 2012.

Smart R.E., Bingham G.E.: Rapid estimates of relative water content. - Plant Physiol. 53: 258-260, 1974.

Smith H.: Sensing the light environment: the functions of the phytochrome family. - In: Kendrick R.E., Knronenberg G.H.M. (ed.): Photomorphogenesis in Plants. Pp. 377-416. Springer, Dordrecht 1994.

Smith H.: Phytochromes and light signal perception by plants an emerging synthesis. - Nature 407: 585-591, 2000.

Sytar O., Zivcak M., Neugart S. et al:: Precultivation of young seedlings under different color shades modifies the accumulation of phenolic compounds in Cichorium leaves in later growth phases. - Environ. Exp. Bot. 165: 30-38, 2019.

Usami T., Mochizuki H., Kondo M. et al.: Cryptochromes and phytochromes synergistically regulate Arabidopsis root greening under blue light. - Plant Cell Physiol. 45: 1798$1808,2004$.

Wang H., Gu M., Cui J. et al.: Effects of light quality on $\mathrm{CO}_{2}$ assimilation, chlorophyll-fluorescence quenching, expression of Calvin cycle genes and carbohydrate accumulation in Cucumis sativus. - J Photoch. Photobio. B 96: 30-37, 2009.

Wang H., Jiang Y.P., Yu H.J. et al.: Light quality affects incidence of powdery mildew, expression of defence-related genes and associated metabolism in cucumber plants. - Eur. J. Plant Pathol. 127: 125-135, 2010.

Williamson C.E., Zepp R.G., Lucas R.M. et al.: Solar ultraviolet radiation in a changing climate. - Nat. Clim. Change 4: 434441, 2014.

Xia M.: [Effect of environmental factors on the formation and abscission of flowers and pods.] - J. Sichuan Agric. Univ. 019: 348-351, 2001. [In Chinese] doi:10.16036/j.issn.10002650.2001.04.009

Yamane K., Hayakawa K., Kawasaki M. et al.: Bundle sheath chloroplasts of rice are more sensitive to drought stress than mesophyll chloroplasts. - J. Plant Physiol. 160: 1319-1327, 2003.

Yeats T.H., Rose J.K.C.: The formation and function of plant cuticles. - Plant Physiol. 163: 5-20, 2013.

Yuan G.F., Jia C.G., Li Z. et al.: Effect of brassinosteroids on drought resistance and abscisic acid concentration in tomato under water stress. - Sci. Hortic.-Amsterdam 126: 103-108, 2010.

Zhang T., Shi Y., Piao F., Sun Z.: Effects of different LED sources on the growth and nitrogen metabolism of lettuce. - Plant Cell Tiss. Org. 134: 231-240, 2018.

Zhang Z., Wei W., Zhu H. et al.: W3 is a new wax locus that is essential for biosynthesis of $\beta$-diketone, development of glaucousness, and reduction of cuticle permeability in common wheat. - PLoS ONE 10: e0140524, 2015.

(C) The authors. This is an open access article distributed under the terms of the Creative Commons BY-NC-ND Licence. 